Pacific Journal of Mathematics

PERMUTATIONS OF THE POSITIVE INTEGERS WITH
RESTRICTIONS ON THE SEQUENCE OF DIFFERENCES 


\title{
PERMUTATIONS OF THE POSITIVE INTEGERS WITH RESTRICTIONS ON THE SEQUENCE OF DIFFERENCES
}

\author{
Peter J. Slater and William Yslas Vélez
}

Let $\left\{a_{k}\right\}$ be a sequence of positive integers and $d_{k}=\left|a_{k+1}-a_{k}\right|$. We say that $\left\{a_{k}\right\}$ is a permutation if every positive integer appears once and only once in the sequence, $\left\{a_{k}\right\}$. We prove the following: Let $\left\{\boldsymbol{m}_{i}\right\}$ be any sequence of positive integers, then there exists a permutation $\left\{a_{k}\right\}$ such that $\left|\left\{k \mid d_{k}=i\right\}\right|=m_{i}$.

By a permutation $\left\{a_{k} \mid k \in N\right\}$, where $N$ denotes the set of positive integers, we shall mean a sequence of positive integers such that every element of $N$ appears once and only once in the sequence $\left\{a_{k} \mid k \in N\right\}$. Set $d_{k}=\left|a_{k+1}-a_{k}\right|$. The purpose of this paper is to answer, in the affirmative, two questions which were raised by Roger Entringer at the University of New Mexico.

Question 1. Can one construct a permutation $\left\{a_{k} \mid k \in N\right\}$ such that given any interger $n,\left|\left\{k \mid d_{k}=n\right\}\right| \leqq C$, where $C$ is some fixed constant which is independent of $n$ ?

Question 2. Can one construct a permutation $\left\{a_{k} \mid k \in N\right\}$ such that $\left\{d_{k} \mid k \in N\right\}$ is also a permutation?

These questions are similar in nature to a problem described in [2] as having been solved by M. Hall. A solution by J. Browkin appears in [1], and the problem is to find a subset $A$ of $N$ such that every natural number is the difference of precisely one pair of numbers of the set $A$. Note that in this problem one considers all differences and not just differences formed by adjacent members in a sequence.

Let us consider the following procedure for constructing a sequence. Let $a_{1}=1, a_{2}=2$. We define $a_{3}$ as follows: Let $a_{3}$ be the smallest integer, which has not already appeared in the sequence, such that the difference $\left|a_{3}-a_{2}\right|$ has also not appeared. Clearly, $a_{3}=4$. Assume that $a_{1}, a_{2}, \cdots, a_{t}$ have been defined in this way. Define $a_{t+1}$ by the following conditions: (i) $\left|a_{t+1}-a_{t}\right| \neq d_{i}, i<t$, (ii) $a_{t+1} \neq a_{i}, i<t+1$, and (iii) $a_{t+1}$ is the smallest positive integer with properties (i) and (ii).

Clearly, every integer appears at most once in the sequences $\left\{a_{k} \mid k \in N\right\}$ and $\left\{d_{k} \mid k \in N\right\}$. But are these sequences permutations? The next theorem settles this question for the sequence $\left\{a_{k} \mid k \in N\right\}$.

THEOREM 1. The sequence, $\left\{a_{k} \mid k \in N\right\}$, constructed above is a permutation. 
Proof. Assume that this sequence is not a permutation. Let $i$ be the smallest integer which does not appear in the sequence. Choose $k$ so that $\{1,2, \cdots, i-1\} \subset\left\{a_{1}, \cdots, a_{k}\right\}$. Choose subscripts $k_{1}, k_{2}, \cdots, k_{i+1}$ such that $k+1 \leqq k_{1}<k_{2}<\cdots<k_{i+1}$ and $a_{k_{j}}>a_{l}$, for $l<k_{j}$, that is, $a_{k_{j}}$ is the largest integer to appear in $\left\{a_{1}, \cdots, a_{k_{j}}\right\}$. Let $M=\max$ $\left\{d_{j} \mid j=1, \cdots, k_{i+1}-1\right\}, M_{1}=\max \left\{d_{j} \mid j=1, \cdots, k_{1}-1\right\}, M_{2}=\max$ $\left\{d_{j} \mid j=k-1, \cdots, k_{i+1}-1\right\}$. Then $M=\max \left\{M_{1}, M_{2}\right\}$. But $M_{1} \leqq a_{k_{1}}-1$ and $M_{2} \leqq a_{k_{i+1}}-(i+1)$, since the smallest integer appearing in the sequence $\left\{a_{k+1}, a_{k+2}, \cdots, a_{k_{i+1}}\right\}$ is larger than or equal to $(i+1)$. Hence $M \leqq \max \left\{a_{k_{1}}-1, a_{k_{i+1}}-(i+1)\right\}$. But $a_{k_{1}}-1 \leqq a_{k_{2}}-2 \leqq \cdots \leqq a_{k_{i+1}}$ $-(i+1)$. So $M \leqq a_{k_{i+1}}-(i+1)<a_{k_{i+1}}-i$. Hence $a_{k_{i+1}}-i>d_{j}$, $j=1, \cdots, k_{i+1}-1$, and $i$ is the smallest integer which has not been used, so we must have that $\alpha_{k_{i+1}+1}=i$, which is a contradiction.

We have not been able to determine whether or not the sequence $\left\{d_{k} \mid k \in N\right\}$ is a permutation.

We next consider another way of constructing permutations so that the differences are also a permutation.

We say that $\left\{a_{1}, \cdots, a_{t}\right\}$ has property 1 if the $a_{i}$ are distinct and the $d_{i}=\left|a_{i+1}-a_{i}\right|, i=1, \cdots, t-1$, are also distinct.

Let $i_{t}$ be the smallest integer not appearing in the set $\left\{a_{1}, \cdots, a_{t}\right\}$, $e_{t}$ is the smallest integer not appearing in the set $\left\{d_{1}, \cdots, d_{t-1}\right\}, I_{t}=\max$ $\left\{a_{1}, \cdots, a_{t}\right\}, E_{t}=\max \left\{d_{1}, \cdots, d_{t-1}\right\}$. Clearly $E_{t}<I_{t}$.

REMARK. Note that either $e_{t}<E_{t}$ or $e_{t}=E_{t}+1$. In either case we have that $e_{t} \leqq I_{t}$.

Rule 1. Set $a_{t+1}=2 I_{t}+1$. If $e_{t} \leqq i_{t}$, then set $a_{t+2}=a_{t+1}-e_{t}$. If $e_{t}>i_{t}$, then set $a_{t+2}=i_{t}$.

LemMa 1. If $\left\{a_{1}, \cdots, a_{t}\right\}$ has property 1 and $a_{t+1}, a_{t+2}$ are constructed according to Rule 1 , then $\left\{a_{1}, \cdots, a_{t}, a_{t+1}, a_{t+2}\right\}$ also has property 1.

Proof. Clearly $a_{t+1} \cap\left\{a_{1}, \cdots, a_{t}\right\}=\varnothing$ and $d_{t}=a_{t+1}-a_{t}=2 I_{t}+1-a_{t}=$ $I_{t}+1+\left(I_{t}-a_{t}\right) \geqq I_{t}+1>E_{t}$, so $d_{t} \cap\left\{d_{1}, \cdots, d_{t-1}\right\}=\varnothing$.

Assume that $e_{t} \leqq i_{t}$. Then $a_{t+2}=2 I_{t}+1-e_{t}=I_{t}+1+\left(I_{t}-e_{t}\right) \geqq I_{t}+1$. Hence $\left\{a_{t+2}\right\} \cap\left\{a_{1}, \cdots, a_{t}\right\}=\varnothing$, so $\left\{a_{1}, \cdots, a_{t}, a_{t+1}, a_{t+2}\right\}$ are $t+2$ distinct integers. Further $d_{t+1}=\left|a_{t+2}-a_{t+1}\right|=e_{t}$, so $\left\{d_{1}, \cdots, d_{t+1}\right\}$ are $t+1$ distinct differences, hence $\left\{a_{1}, \cdots, a_{t+2}\right\}$ has property 1 .

Assume that $i_{t}<e_{t}$. Then $a_{t+2}=i_{t}$, so $\left\{a_{1}, \cdots, a_{t+2}\right\}$ are $t+2$ distinct integers. Further $d_{t+1}=2 I_{t}+1-i_{t}=I_{t}+1+\left(I_{t}-i_{t}\right)>$ $\left(I_{t}+1\right)+\left(I_{t}-e_{t}\right) \geqq I_{t}+1>E_{t}$. So $\left\{d_{t+1}\right\} \cap\left\{d_{1}, \cdots, d_{t}\right\}=\varnothing$, hence $\left\{a_{1}, \cdots, a_{t}, a_{t+1}, a_{+2}\right\}$ has property 1 . 
Since $\left\{a_{1}, \cdots, a_{t+2}\right\}$ now has property 1 , we can apply Rule 1 to this sequence and obtain the sequence $\left\{a_{1}, \cdots, a_{t+4}\right\}$, which again has property 1.

THEOREM 2. Let $\left\{a_{1}, \cdots, a_{t}\right\}$ have property 1 and assume that the infinite sequence $\left\{a_{1}, \cdots, a_{t}, a_{t+1}, \cdots\right\}$ is obtained from $\left\{a_{1}, \cdots, a_{t}\right\}$ by applying Rule 1 successively, then the sequences $\left\{a_{k} \mid k \in N\right\}$ and $\left\{d_{k} \mid k \in N\right\}$ are both permutations.

Proof. If $e_{t} \leqq i_{t}$, then $d_{t+1}=e_{t}$. Hence the smallest difference which has not appeared in $\left\{d_{1}, \cdots, d_{t+1}\right\}$ is larger than $e_{t}$, while $i_{t}$ is still the smallest integer which has not appeared in $\left\{a_{1}, \cdots, a_{t+2}\right\}$. If $i_{t}<e_{t}$, then just the opposite happens. We have that $a_{t+2}=i_{t}$ while the smallest difference which has not appeared in $\left\{d_{1}, \cdots, d_{t+1}\right\}$ is still $e_{t}$. From these remarks the theorem follows by induction.

Let $\left\{m_{1}, m_{2}, \cdots\right\}$ be any sequence of positive integers. Then by a slight variation we can obtain a permutation $\left\{a_{k} \mid k_{k} \in N\right\}$ such that $\left|\left\{i \mid d_{i}=j\right\}\right|=m_{j}$.

We say that $\left\{a_{1}, \cdots, a_{t}\right\}$ has property 2 if the $a_{\imath}$ are distinct and $\left|\left\{i \mid d_{i}=j, i<t\right\}\right| \leqq m_{j}$, for all $j$.

Let $i_{t}, I_{t}, E_{t}$ be defined as before. Let $e_{t}$ be the smallest integer such that $\left|\left\{i \mid d_{i}=j, i<t\right\}\right|=m_{j}$, for $j<e_{t}$, and $\left|\left\{i \mid d_{i}=e_{t}, i<t\right\}\right|<m_{e_{t}}$. As before, we have that $E_{t}<I_{t}$ and $e_{t} \leqq I_{t}$.

Lemma 2. Assume that $\left\{a_{1}, \cdots, a_{t}\right\}$ has property 2 and that $a_{t+1}, a_{t+2}$ are defined according to Rule 1 , then $\left\{a_{1}, \cdots, a_{t}, a_{t+1}, a_{t+2}\right\}$ also has property 2.

Proof. The proof is exactly the same as Lemma 1.

THEOREM 3. Let $\left\{m_{1}, m_{2}, \cdots\right\}$ be any infinite sequence of positive integers and let $\left\{a_{1}, a_{2}, \cdots, a_{t}\right\}$ be a sequence which satisfies property 2. If the sequence $\left\{a_{1}, \cdots, a_{t}, a_{t+1}, \cdots\right\}$ is obtained by successively applying Rule 1, then this sequence is a permutation and it also has the property that $\left|\left\{i \mid d_{i}=j\right\}\right|=m_{j}$.

Proof. The proof follows by induction.

REMARK. There are sequences which satisfy property 2, for example, $\left\{a_{1}, a_{2}\right\}$, where $a_{1} \neq a_{2}$.

\section{REFERENCES}

1. J. Browkin, Solution of a certain problem of A. Schinzel, Prace Mat., 3 (1959), 205-207. 
2. W. Sierpinski, Elementary Theory of Numbers, WARSAW, (1964), 411-412.

Received April 28, 1976 and in revised form November 22, 1976. This work was supported by the U. S. Energy Research and Development Administration (ERDA) under Contract No. AT (29-1)-789. By acceptance of this article, the publisher and/or recipient acknowledges the U.S. Government's right to retain a nonexclusive, royalty-free license in and to any copyright covering this paper.

SANDIA LABORATORIES

ALBUQUERQUE, NM 87115 


\section{PACIFIC JOURNAL OF MATHEMATICS}

\section{EDITORS}

RICHARD ARENS (Managing Editor)

University of California

Los Angeles, California 90024

C. W. CURTIS

University of Oregon

Eugene, OR 97403

C. C. MOORE

University of California

Berkeley, CA 94720

\section{J. DugundJI}

Department of Mathematics University of Southern Californıa Los Angeles, California 90007

R. FinN AND J. Milgram Stanford University Stanford, California 94305

\section{ASSOCIATE EDITORS}

E. F. BECKENBACH

B. H. NEUMANN

F. WOLF

K. YOSHIDA

\section{SUPPORTING INSTITUTIONS}

UNIVERSITY OF BRITISH COLUMBIA CALIFORNIA INSTITUTE OF TECHNOLOGY UNIVERSITY OF CALIFORNIA MONTANA STATE UNIVERSITY UNIVERSITY OF NEVADA, RENO NEW MEXICO STATE UNIVERSITY OREGON STATE UNIVERSITY UNIVERSITY OF OREGON OSAKA UNIVERSITY
UNIVERSITY OF SOUTHERN CALIFORNIA STANFORD UNIVERSITY UNIVERSITY OF TOKYO UNIVERSITY OF UTAH WASHINGTON STATE UNIVERSITY UNIVERSITY OF WASHINGTON AMERICAN MATHEMATICAL SOCIETY NAVAL WEAPONS CENTER 


\section{Pacific Journal of Mathematics}

\section{Vol. 71, No. $1 \quad$ November, 1977}

Charalambos D. Aliprantis and Owen Sidney Burkinshaw, On universally complete Riesz spaces ............................. 1

Stephen Richard Bernfeld and Jagdish Chandra, Minimal and maximal solutions of nonlinear boundary value problems .................

John H. E. Cohn, The length of the period of the simple continued fraction of

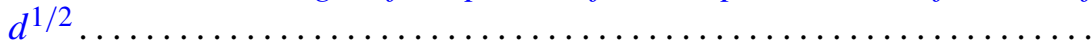

Earl Vern Dudley, Sidon sets associated with a closed subset of a compact abelian group .................................... 33

Larry Finkelstein, Finite groups with a standard component of type $J_{4} \ldots \ldots$

Louise Hay, Alfred Berry Manaster and Joseph Goeffrey Rosenstein, Concerning partial recursive similarity transformations of linearly ordered sets .......................................

Richard Michael Kane, On loop spaces without $p$ torsion. II ............

William A. Kirk and Rainald Schoneberg, Some results on

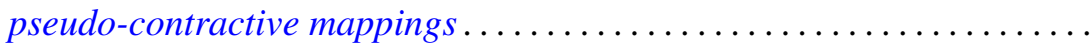

Philip A. Leonard and Kenneth S. Williams, The quadratic and quartic character of certain quadratic units. I. .

Lawrence Carlton Moore, A comparison of the relative uniform topology and the norm topology in a normed Riesz space .................

Mario Petrich, Maximal submonoids of the translational hull 119

Mark Bernard Ramras, Constructing new R-sequences . . .

Dave Riffelmacher, Multiplication alteration and related rigidity properties

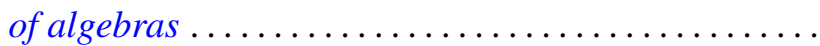

Jan Rosiński and Wojbor Woyczynski, Weakly orthogonally additive functionals, white noise integrals and linear Gaussian stochastic processes.

Ryōtarō Satō, Invariant measures for ergodic semigroups of operators

Peter John Slater and William Yslas Vélez, Permutations of the positive integers with restrictions on the sequence of differences...

Edith Twining Stevenson, Integral representations of algebraic cohomology classes on hypersurfaces ........................

Laif Swanson, Generators of factors of Bernoulli shifts . 